\section{Section 37 Hospital Order}

Sir: I write in reply to $H$. Mathew (Psychiatric Bulletin, June 1996, 20, 375) asking why Section 37 patients cannot apply to a Mental Health Review Tribunal (MHRT) in the first six months of detention. Patients detained on a Section 3 or a Section 37, both of which allow treatment to be given, are given the right to a review of their detention by an independent body with professional members once in the first six months of detention. Thus, those on a Section 3 can apply to a MHRT within the first six months. In the case of a Section 37, the order is imposed by the court, which is regarded as an independent body and therefore the patient is not entitled to a further review by an equivalent body (i.e. a MHRT) within the first six months of detention under the Mental Health Act.

I share the concern at the seemingly anomalous situation which $\mathrm{H}$. Mathew describes.

\section{CHRISTOPHER ClARK}

Alexandra House Day Unit, Nether Edge Hospital, Osborne Road, Sheffield S11 9EL

\section{College guidelines on psychotherapy training}

Sir: The Royal College of Psychiatrists in November 1993 issued new guidelines on psychotherapy training (Grant et al, 1993). I would like to report on progress made towards meeting the guidelines with regard to individual psychotherapy training.

A questionnaire was posted to all 44 registrars on a London-based general psychiatric training scheme. Twenty (64\%) of the 31 career registrars responded compared with only five (38\%) visiting registrars, giving a total response rate of $57 \%$.

It was disappointing to find that only $8 \%$ of the respondents had attended Balint-type seminars, but $17(68 \%)$ reported training with video technology. More encouraging were the findings that $23(92 \%)$ reported psychotherapy casework experience, with $13(52 \%)$ successfully continuing therapy with the same patient despite a change of postings. The majority of respondents (72\%) satisfy the guidelines' requirements for casework experience of at least one long case and two short cases. On the whole, career registrars satisfied the requirements more than visiting registrars.

Regarding supervision, 16 (72\%) received an average of one hour supervision per week, with the majority, 1.e. 12 (54\%), being supervised within groups. The result is that $95 \%$ of the respondents presented their cases for supervision after two or more sessions with the patients. It is perhaps not surprising therefore that $13(59 \%)$ wished for individual as well as group supervision. Surpris- ing, however, is that $64 \%$ of the respondents felt they were receiving adequate supervision. This suggests an inadequate understanding of the purpose and process of supervision.

Despite the many reported difficulties with pursuing a training in psychotherapy (poor consultant support, rotating posts, inadequate time and other logistic problems etc.), $52 \%$ reported satisfaction with the overall training.

Grant, S., Holmes, J. \& WATSON, J. (1993) Guidelines for psychotherapy training as part of general professional psychiatric training. Psychiatric Bulletin, 17, 695-698.

LARTEQUE LAWSON

Psychiatry of Learning Disability. Bridge Hospital, Witham, Essex

\section{High dose antipsychotic prescribing}

Sir: Hillam and colleagues (Psychiatric Bulletin, February 1996, 20, 82-84) and Haw \& Morgan (Psychiatric Bulletin, May 1996, 20, 311) both debate the merits and demerits of calculating neuroleptic dosages in terms of chlorpromazine equivalence, but they do not proceed to use the consensus statement to set standards in such prescribing.

We have examined antipsychotic prescribing in our Forensic Unit by point prevalence survey. Bed occupancy on the day of the survey in April 1996 was $98 \%(n=42)$. A chlorpromazine equitvalence figure was calculated for all regularly prescribed oral and depot drugs using data from the Psychotropic Drug Directory (Bazire, 1995). We identified 13 patients (31\%) who were receiving prescription for "high dose" antipsychotic drugs.

Following the initial survey, we have adopted the following practical approach to comply with concensus guidelines.

(1) All patients identified in our survey and those prospectively identified in 2 (see below) have the drug prescription kardex marked with a fluorescent orange "high dose antipsychotic prescription" marker with the date of instigation of such prescribing.

(2) At the weekly ward round, the team pharmacist identifies any new or current patient who has entered this category.

(3) At the above review patients highlighted as being in receipt of a high dose prescription have duration of treatment and its efficacy monitored. Survelllance for co-prescription of $\mathrm{QT}$ interval prolonging drugs as defined by the CSM is included here.

(4) All patients on high dose regimes are offered ECG examination and those remaining on such regimes beyond three 